\title{
Consultation Program for Patients with Cancer-Related Fatigue: A Systematic Evaluation of the Experiences of the Bavarian Cancer Society
}

\author{
Irene Fischer ${ }^{a, b, c}$ Carola Riedner ${ }^{b, d}$ Peter Bojko ${ }^{b, e}$ Manfred E. Heim ${ }^{b, c, f}$ Jens U. Rüffer ${ }^{c}$ \\ Markus Besseler ${ }^{b, g}$ Pia Heußner ${ }^{b, g, h} \quad V^{b}$ aleria Milani ${ }^{b, i}$ Nina Rinas ${ }^{b, j} \quad$ Günter Schlimok $^{g}$ \\ Erhard Schneider ${ }^{b, k}$ Michael Koller'

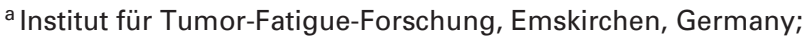 \\ ${ }^{b}$ AG Tumor-Fatigue in der BKG e.V., Munich, Germany; \\ ${ }^{\mathrm{c}}$ Deutsche Fatigue Gesellschaft e.V., Cologne, Germany; \\ ${ }^{\mathrm{d}}$ Krebsberatungsstelle am Tumorzentrum München in Kooperation mit der Bayerischen Krebsgesellschaft e.V., Munich, Germany;

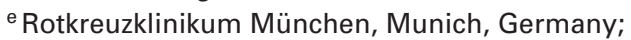 \\ ${ }^{f}$ Gesundheitszentrum Bodensee, Klinik Sokrates, Güttingen, Switzerland; \\ ${ }^{9}$ Bayerische Krebsgesellschaft e.V., Munich, Germany; \\ hPsycho-Onkologie Medizinische Klinik III und CCC LMU, Klinikum der LMU-Großhadern, Munich, Germany; \\ i Facharztzentrum Fürstenfeldbruck, Fürstenfeldbruck, Germany; \\ j Klinik Herzoghöhe, Bayreuth, Germany; \\ ${ }^{k}$ Praxis für Psychosomatische Medizin und Psychotherapie, Psychoonkologie, Traumatherapie, Wangen, Germany; \\ I Zentrum für Klinische Studien, Universitätsklinikum Regensburg, Regensburg, Germany
}

\section{Keywords}

Cancer-related fatigue: diagnostics, treatment, counseling · Fatigue, cancer - Consultation hour . Management

\section{Background}

Cancer-related fatigue (CRF) is a subjective condition of atypical physical, affective, and cognitive tiredness and exhaustion [1]. Hampering daily life [2], CRF can be a relevant problem for such patients and CRF is also associated with a shortened overall survival [3]. Despite availability of evidence-based treatment options [4-6], many patients with CRF feel insufficiently cared for $[7,8]$. As, to date, there is no International Classification of Diseases (ICD) code for CRF, the most suitably way to close this care gap is through a nonprofit organization such as the Bavarian Cancer Society e.V. (BKG).

Thus, together with the 'Institut für Tumor-Fatigue-Forschung' (ITFF), the BKG has started to develop a health care structure in Bavaria by offering free special consultation hours (CHS). These are currently available at the psychosocial cancer counseling centers (PCCC) Bayreuth, Kempten, Nuremberg and Munich, and with an external cooperation partner in Fürstenfeldbruck [9]. More facilities are being planned. Except at Nuremberg, all CHS are directed by physicians with oncological and psycho-oncological experience. Before the start, all took part in an extensive CRF management training. This paper provides information about CHS procedures, the patients and their problems with CRF, the results of a systematical evaluation and the challenges connected with the establishment of regular CHS.

\section{Methods}

\section{CRF Consultation Hour at the BKG e.V.}

The BKG is a non-profit organization with 19 outpatient PCCC and psycho-oncological services, and carries out approximately 23,000 counseling sessions per year. Patients who express serious complaints of exhaustion on this occasion will get an appointment for the CHS.

At the first consultation (duration 60-90 min) (differential-)diagnosis is made mainly by standardized anamnesis (compiled with a modified version of the anamnesis guideline of the German Fatigue Society [10]), the Brief Fatigue Inventory (BFI [11]) and inspection of the patient's records. The standardized anamnesis includes the topics: symptoms and intensity of CRF, impairment, beginning, course, earlier states of exhaustion, differences as compared to normal tiredness, cancer anamnesis, co-morbidities including depression, current

\section{KARGER}

(c) 2016 S. Karger GmbH, Freiburg 


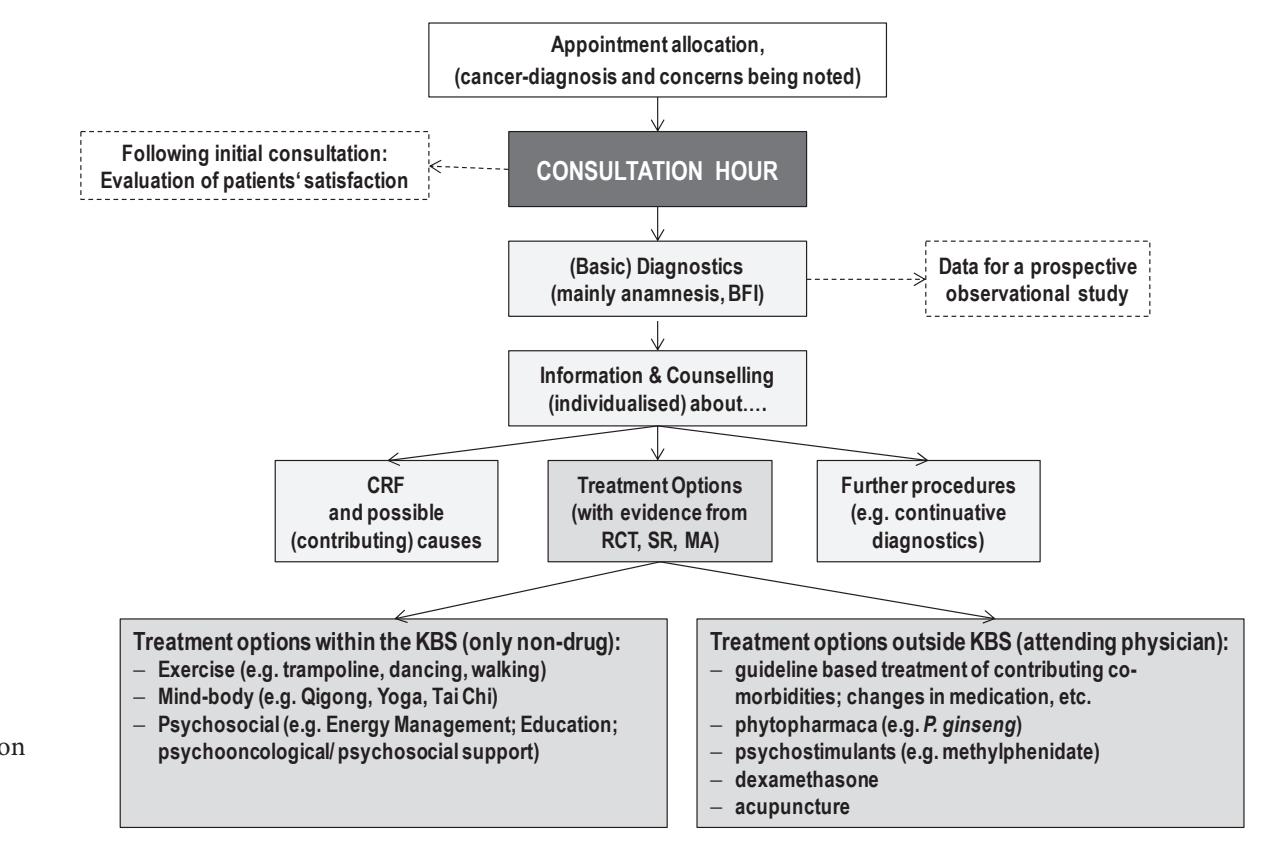

Fig. 1. Cancer-related fatigue (CRF) consultatio hour of the Bavarian Cancer Society e.V. (BKG): Procedure.

medication, vegetative anamnesis, and social anamnesis. The BFI comprises 9 items with a numerical analogue scale from 0 to 10 to determine severity and impairment of the CRF (0-3 low, 4-7 moderate, 8-10 serious severity or impairment).

In an individualized counseling interview, the patient is informed about CRF, potential contributing factors, further diagnostic procedures if necessary and symptomatic treatment options with evidence from randomized controlled clinical trials (RCT), systematic reviews and meta-analysis. Following a shared decision-making approach, possible treatment options are discussed and defined with the patient. The procedure for the CRF consultation hour of the BKG is shown in figure 1. Diagnostics and counseling are systematically documented.

Potential treatment within the PCCC is restricted to psycho-oncological supervision and non-pharmacological symptomatic treatment. For this purpose, the BKG offers amongst other things special courses, e.g. Qigong. For causal treatment of contributing factors (e.g. therapy for comorbidities) and symptomatic treatment options that cannot be provided by the PCCC (e.g. acupuncture), the patient is referred to his physician, who can contact the original counselor at any time. As part of a Swiss study, suitable patients could stay 3 weeks without costs in the oncological REHA Clinic Sokrates at CH-Güttingen, which is specialized in the treatment of CRF.

\section{Evaluation Design}

We performed a prospective, observational questionnaire study to evaluate patients' perception of the consultation program for CRF. The project was reported to the Academy for Ethics in Medicine (Göttingen), which responded favorably on 21 July 2013. All patients gave their informed consent that their data can be used in anonymous, statistical analyses.

After the initial consultation patients were asked to fill in an anonymous evaluation questionnaire about the CHS, which was sent to the office of the tumor center of the University of Erlangen-Nuremberg for analysis. Because there is no assessment tool for the evaluation of a CRF-CHS, we developed a questionnaire with 12 closed-ended questions, 4 open-ended questions and 1 pitch to note question. All questions had a high face validity.

\section{Analysis}

All the data collected in the CHS were systematically documented and descriptively evaluated. The answers to the open-ended questions on the evaluation questionnaire were evaluated according to a content analysis, which belongs to the qualitative methods. The approach is described below.

\section{Results}

From September 2013 to December 2015, 269 patients with CRF visited the CHS (pilot phase Nuremberg in 2013-2014, $\mathrm{n}=51$; follow-up stage 1 at 5 sites in 2015, $\mathrm{n}=218)$ [12]. Most of the patients came from the local area (62\% within $0-25 \mathrm{~km}, 18 \%$ within $26-50 \mathrm{~km}$, and $18 \%$ withing $51-100 \mathrm{~km})$. According to the BFI, nearly $2 / 3$ of the patients had a moderate and $1 / 3$ a serious CRF. $21 \%$ of the patients felt too tired to follow their doctor's recommendations (table 1).

In the majority of patients the exhaustion began close to the time of the initial tumor diagnosis or initial therapy, but there were also patients who dated the beginning many years before their initial tumor diagnosis or many years after successful curative treatment. However, in order not to overlook treatable contributing factors, it has been found useful to examine at what date and in what specific situation the problems began. For example, there may have been a major depression, which has been observed more frequently in our patients with CRF (44\%) than reported in the literature [13], or any other problem.

\section{Evaluation}

Completed questionnaires were returned by 251 of 269 patients. Taken together patients were very satisfied with the pattern, duration and content of the CHS. Figure 2 shows the results of the (closed-ended) statement questions. In addition, 4 open-ended questions were asked: (a) What did you like about the consultation hour? (b) What did you not like? (c) What did you miss? And (d) What could we do better?

The answers were verbatim transcribed in the office of the tumor center of the University of Erlangen-Nuremberg and subsequent content analyzed by I. Fischer (ITFF) according to Mayring [14]. For this purpose, for each question, similar statements were classified into empirically derived categories, which were then 
Table 1. Patient characteristics

\begin{tabular}{|c|c|}
\hline Total, n (\% female) & $269(78)$ \\
\hline Age, years (mean) & $24-87(55.3)$ \\
\hline \multicolumn{2}{|l|}{ Most common types of cancer, $\%$} \\
\hline Gynaecological (mainly breast $\left(85 \%^{\mathrm{a}}\right)$ and ovaries) & 53 \\
\hline Hematological (mainly NHL, HD, MPN) & 15 \\
\hline Gastrointestinal (mainly colon, stomach) & 10 \\
\hline Urological (mainly prostate, kidney) & 8 \\
\hline Sarcoma & 5 \\
\hline \multicolumn{2}{|c|}{ Disease and treatment situation (most frequent situations), \% } \\
\hline Tumor locally limited & 49 \\
\hline Locally advanced & 9 \\
\hline Only lymph node metastasis & 20 \\
\hline Distant metastasis & 18 \\
\hline Situation unclear & 4 \\
\hline Currently no cancer treatment & 54 \\
\hline \multicolumn{2}{|l|}{ Average fatigue (BFI, past 7 days) ${ }^{\mathrm{b}}, \%$} \\
\hline $0-3$ & 5 \\
\hline $4-7$ & 64 \\
\hline $8-10$ & 31 \\
\hline \multicolumn{2}{|l|}{ Impairment of general activity (BFI, past 7 days) ${ }^{c}, \%$} \\
\hline $0-3$ & 3 \\
\hline $4-7$ & 57 \\
\hline $8-10$ & 40 \\
\hline \multicolumn{2}{|l|}{ First manifestation of $\mathrm{CRF}^{\mathrm{d}}, \%$} \\
\hline \multicolumn{2}{|l|}{ Time before primary cancer diagnosis } \\
\hline $6-65$ years & 4 \\
\hline $3-5$ years & 3 \\
\hline 2 years & 4 \\
\hline 1 year & 7 \\
\hline During year of cancer diagnosis & 47 \\
\hline \multicolumn{2}{|l|}{ Time after primary cancer diagnosis } \\
\hline 1 year & 15 \\
\hline 2 years & 4 \\
\hline $3-5$ years & 8 \\
\hline $6-21$ years & 8 \\
\hline \multicolumn{2}{|l|}{ Number of days with fatigue (past 4 weeks) ${ }^{e}, \%$} \\
\hline Every day & 55 \\
\hline $21-26$ days & 8 \\
\hline 16-20 days & 14 \\
\hline $11-15$ days & 13 \\
\hline$<10$ days & 11 \\
\hline
\end{tabular}

${ }^{\text {a} B a s e: ~} \mathrm{n}=114$ with gynecological cancers.

b'Base $\mathrm{n}=213$ of 218 (BFI not used in the pilot phase); mean: 7.1.

${ }^{c} 208$ of 218 patients answered question (BFI not used in the pilot phase); mean 6.6.

$\mathrm{d}_{2} 253$ of 269 patients answered question.

e 244 of 269 patients answered question; mean: 22.4 days.

$\mathrm{NHL}=$ non-Hodgkin disease, $\mathrm{HD}=$ Hodgkin disease, $\mathrm{MPN}=$ myeloprolifera tive neoplasias, BFI = Brief Fatigue Inventory (0-3 low, 4-7 moderate, 8-10 serious severity or impairment), $\mathrm{CRF}=$ cancer-related fatigue.

grouped into empirically derived main categories. The number of patients who made a statement relevant to each category was counted. To quantify the main categories, net values were established, i.e. each patient was counted only once, regardless of the number of statements in the sub-categories. The determined frequency was subsequently figured in percentage for the whole group. Table 2 shows the most important categories for question (a), answered by $83 \%$ of the patients, as well as the share of the patients in the individual categories.

The feedback to the 'critical questions' (b), (c) and (d) showed that only $8 \%$ of the patients expressed dissatisfaction. The most frequent complaint was that the session was too short. The answers to question (c) (what did you think was missing?) reflect only individual needs. Considering question (d), 15\% of the patients made suggestions for improvements: mainly that the CHS should be made more popular, and that follow-up sessions be offered. The average mark for all CHS was 1.2.

\section{Discussion}

CRF is a debilitating condition of atypical exhaustion in the context of cancer and its therapy. During cancer therapy most cancer patients suffer from CRF, and during aftercare $20-50 \%$ are affected [15], women slightly more often than men [16]. CRF is not only a problem for the patient but also for the family. Being a predictor for return to work after cancer, CRF has consequences for the health economy [17]. However, many patients feel that the care standard for their condition is insufficient $[7,8]$. Thus, the BKG, together with the ITFF, is planning a comprehensive health care structure in Bavaria by offering free CHS, which is currently available in 5 Bavarian cities. In the first 2 years 269 , mostly female, patients had appointments. Of these patients, $64 \%$ had a moderate, and $31 \%$ a serious CRF. On average, patients have felt exhausted on 22.4 days per month and for 4.2 years (range 2 months to 67 years), predominantly beginning at the time of initial cancer diagnosis or primary treatment. $57 \%$ of the patients feel that their everyday activities are moderately and $40 \%$ severely impaired by CRF. That CRF prevents every fifth patient from following his doctor's recommendations could be clinically relevant and should be investigated further.

The CHS are being evaluated continuously. Up to now, 93\% of the patients have participated in the evaluation. The CHS are judged to be very good and helpful. Nevertheless, the number of CRF patients who have had an appointment in the CHS up to now is surprisingly low, considering that during tumor therapy nearly every patient, and during aftercare $20-50 \%$ of patients, suffer from CRF [15]. There can be several reasons for this imbalance: cancer patients who contact a PCCC to get psychosocial support get an appointment for the CHS only if they express serious complaints of being exhausted. The term 'fatigue' is not known to every patient and they do not connect their tiredness or exhaustion to CRF. Thus, they see no reason for an appointment. Others may not be aware of the CHS, have simply resigned themselves to their condition, already have a helpful contact person for this problem or do not suffer from CRF to such an extent that they feel a need to seek help for it. International study results also point to other barriers, which prevent adequate treatment of CRF, e.g. the belief that CRF inevitably belongs to the cancer illness and its treatment, and that no therapy for CRF is available $[18,19]$. 
Table 2. Categories identified by content analysis of all answers to the open-ended question: What did you like about the consultation hour?

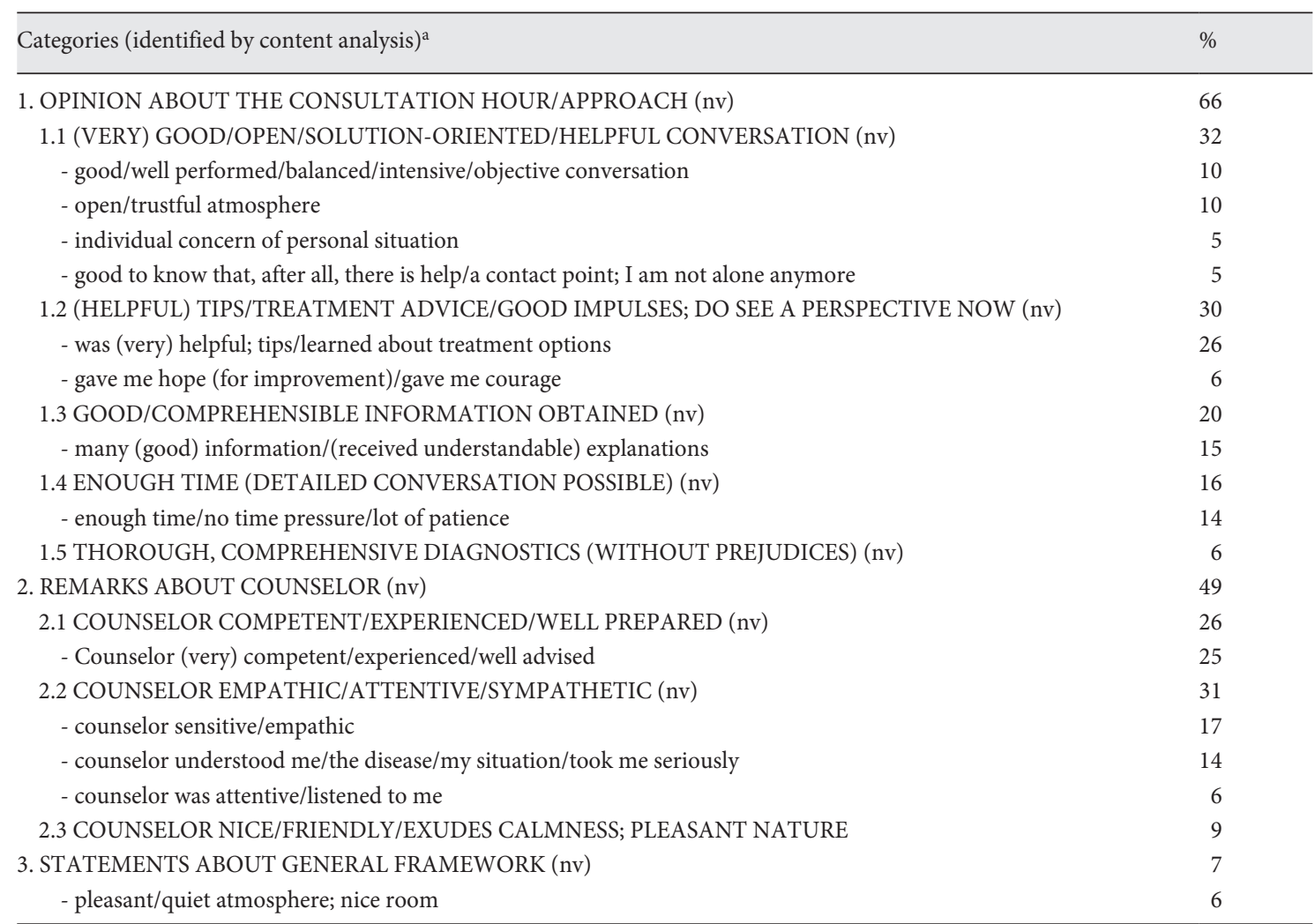

${ }^{a}$ Base: total ( $n=251$ questionnaires; only categories $\geq 5 \%$ shown). $\mathrm{nv}=$ net value.
That such attitudes also play an important role in connection with the CRF-CHS of the BKG was evident in the pilot survey of 63 self-help group leaders. It seems that those affected often doubt if their tiredness is really CRF, maybe due to the experience that persons in their social environment also often complain of being tired. Otherwise, it is often the exhaustion itself that prevents the patients from seeking treatment, especially when a longer journey to the treatment center has to be considered [20].

Almost certainly such a project takes more time than 2 years to get going, which was also seen at the Cancer Fatigue Clinic at MD Anderson Cancer Center [21], by which we have been inspired.

\section{Conclusion}

CRF-CHS at the BKG are currently being offered in 5 Bavarian cities. They are accepted and generally judged by the patients to be very positive. Therefore, we plan to establish CHS (in addition to Bayreuth, Fürstenfeldbruck, Kempten, Munich and Nuremberg) also in Augsburg, Ingolstadt, Passau, Regensburg and Würzburg. In the final stage, all of the CHS should be directed by physicians with oncological and psycho-oncological experience. To reduce the risk of CRF chronification, more attention will be paid to relevant risk factors, like loneliness or anxiety [22]. To evaluate possibly positive long-term effects of the

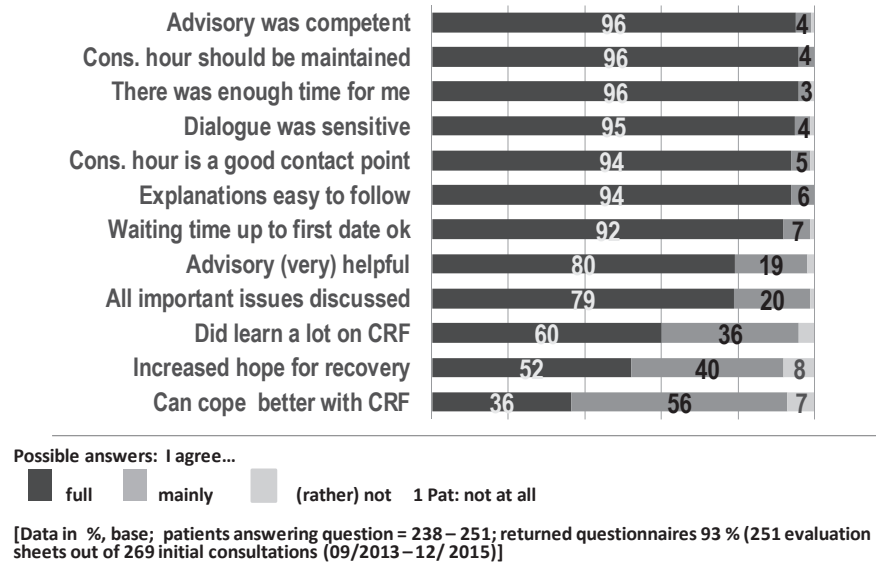

Fig. 2. Patient's evaluation of the consultation hour by means of statements (closed-ended questions) [9] with kind permission.

CHS, a longitudinal study over a year is being planned. In order to change the general opinions about CRF, the barriers that seem to block the CHS need to be lowered. This can be achieved by CRF training courses for doctors, nurses, self-help group leaders and patients, which will be offered by the BKG. Special attention should be paid to the presence of CRF in the PCCC of all regional cancer societies. 


\section{Acknowledgement}

We wish to thank Prof. Konrad Fischer (Technische Hochschule Nuremberg) for his support for the content analysis and Tatjana Einwag (Tumorzentrum Erlangen-Nuremberg) for the analysis of the evaluation questionnaires.

\section{Disclosure Statement}

The authors declare no conflict of interest.

\section{References}

1 NCCN Clinical Practice Guidelines in Oncology: Cancer-Related Fatigue. http://www.nccn.org/professionals/ physician_gls/pdf/fatigue.pdf (last accessed on 4 January 2016).

2 Rüffer JU: Fatigue. Best Practice Onkologie 2008;3: 44-53.

3 Efficace F, Gaidano G, Breccia M, et al.: Prognostic value of self-reported fatigue on overall survival in patients with myelodysplastic syndromes: A multicentre, prospective, observational, cohort study. Lancet Oncol 2015;16:1506-1514.

4 Rüffer JU, Adamietz I: Fatigue - Tumorerschöpfung. Onkologe 2013;19:279-289.

5 Horneber M, Fischer I, Dimeo F, et al.: Tumor-assoziierte Fatigue Epidemiologie, Pathogenese, Diagnostik und Therapie. Dtsch Ärztebl 2014;111:1-16.

6 Heim ME, Feyer P: Das tumorassoziierte Fatigue-Syndrom. J Onkol 2011:42-47.

7 Santin O, Murray L, Prue G, et al.: Self-reported psychosocial needs and health-related quality of life of colorectal cancer survivors. Eur J Oncol Nurs 2015;19: 336-342.

8 Glaus A, Frei IA, Knipping C, et al.: Was Krebskranke von den Informationen über Fatigue halten: Eine Beurteilung durch Patienten in der Schweiz und in England. Pflege 2002;15:187-194.
9 Fischer I, Besseler M, Bojko P, et al.: Tumor-Fatigue Sprechstunde der Bayerischen Krebsgesellschaft e.V. Was wurde erreicht und wohin geht die Reise? Forum 2016;31:247-251

10 Fischer I, Horneber M, Heim ME, et al.: Anamneseleitfaden, in: Heim ME, Weis J (eds.): Fatigue bei Krebserkrankungen. Stuttgart: Schattauer, 2014

11 Mendoza TR, Wang XS, Cleeland CS, et al.: The rapid assessment of fatigue severity in cancer patients: Use of the Brief Fatigue Inventory. Cancer 1999;85:11861196.

12 Fischer I, Salzmann D, Petsch S, et al.: Tumor-FatigueSprechstunde der Bayerischen Krebsgesellschaft e.V.: Stand der Dinge und aktuelle Entwicklungen. Forum 2015;1:67-70.

13 Weis J: Früherkennung einer Depression verbessert Tumorprognose. Im Focus Onkologie 2015;18:47-49.

14 Mayring P: Kombination und Integration qualitativer und quantitativer Analyse. FQS Forum: Qualitative Sozialforschung Social Research 2001;2:Art. 6.

15 Weis J, Faller H: Psychosoziale Folgen bei Langzeitüberlebenden einer Krebserkrankung. Bundesgesundheitsblatt 2012;55:501-508.
6 Singer S, Kuhnt S, Zwerenz R, et al.: Age- and sexstandardised prevalence rates of fatigue in a large hospital-based sample of cancer patients. Br J Cancer 2011;105:445-451.

17 Weis J: Cancer-related fatigue: Prevalence, assessment and treatment strategies. Expert Rev Pharmacoecon Outcomes Res 2011;11:441-446.

18 Pearson E, Morris ME, McKinstry CE: Cancer-related fatigue: A survey of health practitioner knowledge and practice. Support Care Cancer 2015;23:3521-3529.

19 Passik SD, Kirsh KL, Donaghy K, et al.: Patient-related barriers to fatigue communication: Initial validation of the fatigue management barriers questionnaire. J Pain Symptom Manage 2002;24:481-493.

20 Fischer I, Besseler M: Tumor-Fatigue-Sprechstunde der BKG e.V.: Mögliche Hinderungsgründe für die Inanspruchnahme aus Sicht von Selbsthilfegruppenleitern. Forum 2016;31:72-75

21 Escalante CP, Kallen MA, Valdres RU, et al.: Outcomes of a cancer-related fatigue clinic in a comprehensive cancer center. J Pain Symptom Manage 2010;39:691701.

22 Bower JE: Cancer-related fatigue-mechanisms, risk factors, and treatments. Nat Rev Clin Oncol 2014;11: 597-609. 